\title{
Mesenchymal Stem Cells from the Wharton's Jelly of the Human Umbilical Cord: Biological Properties and Therapeutic Potential
}

\author{
Luigi Marino ${ }^{1}$, Maria Antonietta Castaldi ${ }^{1,2}$, Rosa Rosamilio ${ }^{1}$ Enrico Ragni, \\ Rosa Vitolo $^{1}$, Caterina Fulgione ${ }^{1}$, Salvatore Giovanni Castaldi ${ }^{1}$, Bianca Serio ${ }^{1}$, \\ Rosario Bianco ${ }^{1}$, Maurizio Guida ${ }^{1}$, Carmine Selleri ${ }^{1}$ \\ ${ }^{l}$ Department of Medicine, Surgery and Dentistry, University of Salerno, Salerno, Italy \\ ${ }^{2}$ Department of Obstetrics and Gynecology, Azienda Ospedaliera di Rilievo Nazionale e di Alta Specialità \\ "San Giuseppe Moscati", Avellino, Italy \\ ${ }^{3}$ Orthopedic Biotechnology Laboratory, Galeazzi Orthopedic Institute, Milan, Italy
}

\begin{abstract}
Wharton's jelly mesenchymal stem cells (WJ-MSCs) are a class of stem cells with high differentiative potential, an immuno-privileged status and easy access for collection, which raise no legal or ethical issues. WJ-MSCs exhibit several features of embryonic stem cells, both in the phenotypic and genetic aspects, with only a few differences, such as a shorter doubling time and a more extensive ex vivo expansion capacity. WJ-MSCs have immunomodulatory properties, involving both innate and adaptive immune responses. This review focuses on the role of WJ-MSCs in the management of graft-versus-host disease (GvHD), a life-threatening complication of the allogenic transplantation of hematopoietic stem cells. Different studies documented the beneficial effect of the infusion of WJ-MSCs, even when not fully HLA identical, in patients with severe GvHD, refractory to standard treatment. Finally, we summarized current ongoing clinical trials with WJ-MSCs and their potential in regenerative medicine.
\end{abstract}

Keywords: WJ-MSCs, Immunomodulation, GvHD, Mesenchymal stem cells, Human umbilical cord blood

\section{Introduction}

Mesenchymal stem cells (MSCs) are multipotent stem cells with a self-renewing capacity, able to differentiate into multiple mesenchymal lineages, such as adipocytes,

Received: April 12, 2018, Revised: September 23, 2018,

Accepted: November 30, 2018, Published online: April 30, 2019

Correspondence to Maria Antonietta Castaldi

Department of Obstetrics and Gynecology, Azienda Ospedaliera di Rilievo Nazionale e di Alta Specialità "San Giuseppe Moscati", Avellino 83100, Italy

Tel: +39-00393283619828, Fax: +39-00393283619828

E-mail: mantocastaldi@msn.com

(c) This is an open-access article distributed under the terms of the Creative Commons Attribution Non-Commercial License (http://creativecommons.org/ licenses/by-nc/4.0/), which permits unrestricted non-commercial use, distribution, and reproduction in any medium, provided the original work is properly cited.

Copyright (c) 2019 by the Korean Society for Stem Cell Research chondrocytes, osteocytes, smooth muscle cells, fibroblasts and hematopoietic stroma (1).

These cells were first observed between the late 60s and the early 70 s by Friedenstein et al., who proved the existence of a non-hematopoietic cell population, fibroblastlike cells, plastic-adherent cells derived from bone marrow (1). MSCs have been documented to originate a wide range of cellular types such as adipocytes, chondrocytes, osteocytes, smooth muscle cells, fibroblasts and hematopoietic supportive stroma $(1,2)$. MSC-like cells can been collected from different tissues, such as skeletal muscle, adipose tissue, umbilical cord, synovium, dental pulp, amniotic fluid, as well as fetal blood, liver, bone marrow, lung and heart $(2,3)$.

Although MSCs derive from different tissues, they do share some common features: they do not display the peculiar markers that hematopoietic and endothelial cells express, like Cluster of Differentiation (CD)34, CD45, 
CD11b, CD11c, CD14, CD19, CD79 $\alpha$, CD86, and HLA class II molecules and they do express surface markers, in accordance with the commonly accepted minimal criteria of the International Society for Cellular Therapy (ISCT), such as CD90, CD105, CD44, CD73, CD9, and very low levels of CD80 (4).

MSCs can be divided into two classes: adult and fetal/perinatal MSCs, respectively derived from adult tissues, such as bone marrow (BM-MSCs) and adipose tissue (AD-MSCs) (5), and from fetal/perinatal tissues, that include cells obtained from the embryo/foetus itself and cells obtained from extra-embrionic tissues otherwise known as birth associated tissues, such as placenta umbilical cord, Wharton's jelly mesenchymal stem cells (WJ-MSCs) and amniotic membrane (6). MSCs isolated from adult tissues are most commonly used for therapeutic purposes, despite a very limited proliferative capacity. Instead, MSCs derived from extra embryonic tissues, represent ideal choice for therapeutic use, as they share many characteristics with adult MSCs, like BM-MSCs. Although they retain several features of embryonic stem cells (ESCs) they do not form teratomas (7) and their research does not raise any 3ethical or legal issues related to their applications in regenerative medicine. During their short life, perinatal MSCs, such as WJMSCs, are spared from pro-aging factors. It has also been shown that the age of the donor tissue affects many properties of MSCs (8). All these features open perspectives for the diffusion and engineering of umbilical cord derived MSCs for cell-based therapies. Additionally, fetal MSCs possess an immune-privileged status which makes them a favourable choice for regenerative medical applications (9).

The first description of Wharton's Jelly (WJ) by Thomas Wharton dates back to 1656 . It is a mucous connective tissue of the umbilical cord located between the amniotic epithelium and the umbilical vessels. McElreavey et al. (10), 1991, was the first to isolate MSCs from the WJ portion of the umbilical cord.

Several studies indicate that WJ-MSCs can be used in many fields such as neurological disorders (11), kidney injury (12), lung injury (13), orthopaedic injury (14), liver injury (15), cancer therapy (16).

This review will first attempt to provide a summary of the biology of MSCs derived from WJ and then discuss their potential application for the treatment of immunemediated disorders such as GvHD. Additionally, it aims to provide a panoramic view of the most recent clinical trials involving WJ-MSCs for therapeutic use.

This review includes papers identified through a
MEDLINE and EMBASE search using combinations of the following subject heading terms: WJ-MSCs, Immunomodulation, Graft versus Host Disease (GvHD), Mesenchymal Stem Cells, Human umbilical cord blood.

Of the retrieved articles, 83 papers regarding WJ-MSCs, their biological properties and their therapeutic potential were carefully selected, and therefore added together to describe the therapeutic benefits of WJ-MSCs, in particular their role in the management of GvHD.

\section{Immunomodulatory Property of WJ-MSCs}

A mandatory requisite for allogeneic transplantation is low cellular immunogenicity. The therapeutic utility of the WJ-MSCs is strictly associated with their regenerative and immunomodulatory potential. WJ-MSCs are capable of immune suppression and immune avoidance, making them optimal candidates for cellular therapies in allogenic transplantation. Furthermore, WJ-MSCs exhibit very low expression of Human Leukocyte Antigen (HLA) class I and an absence of HLA-DR $(17,18)$. Additionally, it induces the expansion of regulatory $\mathrm{T}$ cells (Treg), which would contribute to the suppression of the effectors responses to alloantigens (19). WJ-MSCs are not capable of generating in vitro immune responses from allogeneic $\mathrm{T}$ cells (20), suggesting that WJ-MSCs possess a specific low immunogenicity and will be tolerated in allogeneic transplantation. Unlike BM-MSCs, WJ-MSCs produce large amounts of tolerogenic Interleukin (IL)-10, Transforming Growth Factor- $\beta$ (TGF- $\beta$ ) (20-22) and they also express IL-6 and vascular endothelial growth factor (VEGF), which are important for the immunosuppressive capability of MSCs $(20,23)$. The immunosuppressive potential of WJ-MSCs on T lymphocytes (18) was investigated. Soluble factors, such as hepatocyte growth factor (HGF), prostaglandin E2 (PGE2), TGF- $\beta 1$ and indoleamine 2 3-dioxygenase (IDO) (24) may mediate the immunomodulatory effects of MSCs on T cells (Fig. 1). WJ-MSCs, when cultured with $\mathrm{CD} 14+$ monocytes, inhibit their differentiation into mature DCs, both via direct contact and through soluble factors (Fig. 1) (25). The immunomodulatory effects of MSCs concern both the cell-mediated and humoral component of immune system. However, the impact of WJ-MSCs on B cells has been poorly investigated. Until today, only a few studies have been reported: in 2012 Che et al. (26), it was reported that WJ-MSCs, in vitro, are capable of inhibiting $\mathrm{B}$ cell proliferation, differentiation and antibody production; Other authors, however, proved that the WJ-MSCs have no influence on the activation of $\mathrm{B}$ cells (27). Further investigation is needed. 


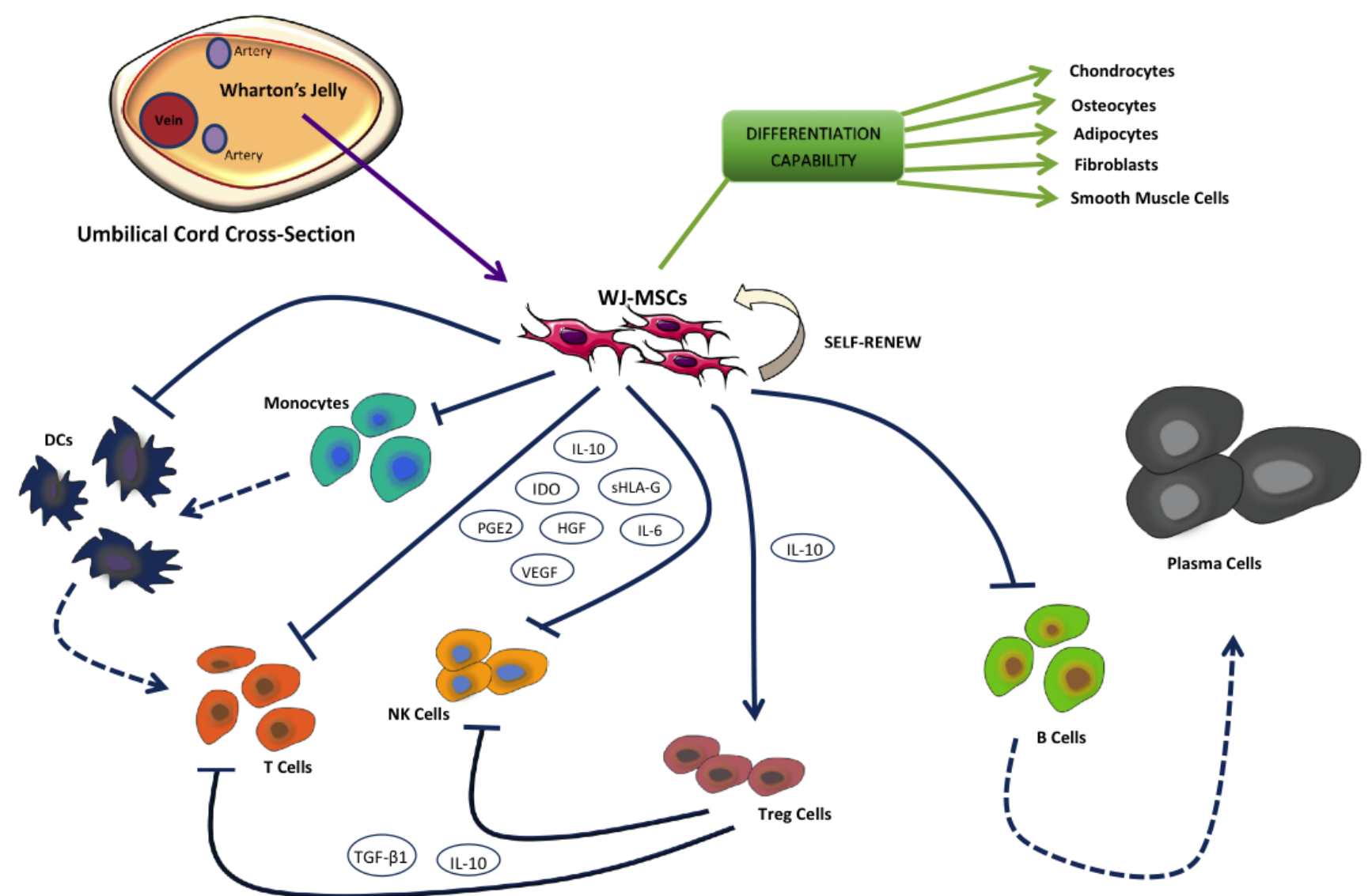

Fig. 1. MSCs mediate immunosuppression of $B, T$ and Natural Killer (NK) cells via different mechanisms. Soluble factors secreted by MSCs such as IDO, PGE2, sHLA-G5 can suppress T and NK cell functions. In addition, MSCs can indirectly mediate immunosuppression by inhibiting dendritic cells (DCs) and inducing the expansion of regulatory $\mathrm{T}$ cells (Tregs).

In summary, immunomodulatory properties of WJ-MSCs, confers upon these cells the potential for therapeutic application.

\section{Phenotypic and Genetic Markers Expression of WJ-MSCs}

WJ-MSCs are good candidates for therapeutic applications because of their primitive features (28), as they exhibit several characteristics of ESCs, such as ESC-like antigen Tra-1-60, Tra-1-81, SSEA-1 and SSEA-4 (29), and numerous pluripotency genes like: Oct-4, NANOG, and SOX-2 (28).

Nekanti et al. (30), in a comparative gene expression profiling study between WJ-MSCs and BM-MSCs, demonstrated that BM-MSCs express higher levels of NANOG, DNMT3B and GABRB3 and an increased expression of Brix, CD9, Gal, Kit and Rexl, a pluripotent/stem cell marker. Their expression is thought to reflect the more primitive nature of WJ-MSCs, compared to their adult counterparts in the bone marrow. These findings, combined with the fact that human WJ-MSCs express the primitive stem cell marker TERT (31) explain, at least in part, the observation that WJ-MSCs have a shorter doubling time (32) and a more extensive in vivo expansion capacity (7).

The most peculiar characteristic of WJ-MSCs is their ability to express the HLA-G6 isoform, implicated, as previously mentioned, in immune-modulation, an essential feature for promoting the use of WJ-MSCs in a cell-based therapy.

WJ provides a generous source of MSCs, and, although WJ-MSCs show some variations in terms of cell quality, it is still a very useful depot of MSCs, with a wide range of potential therapeutic applications.

\section{WJ-MSCs for the Management of Graft-Versus-Host Disease}

Allogeneic hematopoietic stem cell transplantation (allo- 
HSCT), which consists in the infusion of hematopoietic stem cells (HSCs) from a matching donor, is a fundamental therapeutic option for several hematologic malignancies.

In about $50 \%$ of cases, the procedure is complicated by acute or chronic graft-versus-host disease (aGvHD and cGvHD, respectively) and clinical conditions occur when donor-derived $\mathrm{T}$ cells recognize the host cells as non-self and attack them (33).

aGvHD commonly involves the skin, intestinal tract and liver, frequently manifesting itself as a maculopapular rash, nausea, vomiting, diarrhea and hepatic cholestasis. cGvHD generally occurs after 100 days from the transplantation and leads to inflammation and fibrosis of involved organs, presenting as sicca syndrome-like, scleroderma-like skin, cytopenias, chronic pulmonary fibrosis, hepatic and intestinal diseases (34).

The main risk factor associated with the development and severity of GvHD is that the HLA may mismatch between donor and recipient.

The primary treatment for both aGvHD and cGvHD involves immunosuppression by glucocorticoids, with a response rate ranging from 30 to $50 \%$. On the contrary, many immunosuppressive strategies have been studied for steroid-resistant aGvHD (such as mycophenolate mofetil, pentostatin, monoclonal antibodies directed against $\mathrm{T}$ lymphocytes, cytokines and their receptors, mTOR inhibitors and extracorporeal photopheresis) but none have proven to have a consistent effectiveness and safety level (35), so aGvHD is still characterized by a poor prognosis and a Treatment-related mortality (TRM) $>50 \%$ reported in several studies (33). Therefore, alternative strategies are needed to treat GvHD.

Promising treatments for steroid-refractory aGvHD involve the infusion of ex vivo expanded MSCs. The majority of data published reported the use of the BM as standard source of MSCs for human clinical applications. However, to harvest the MSCs from BM a painful, invasive procedure with certain risks is required.

Kang-Hsi Wu et al. in 2011 reported the first case of Wharton's Jelly derived MSCs used in a human clinical application, in two pediatric patients with severe steroid-resistant aGvHD (36).

The first patient was a 4-year-old boy who required an unrelated 6/6 HLA-matched allo-HSCT for severe aplastic anemia not responding to immunosuppression. On day 45, the patient developed an aGvHD with vomiting, hyperbilirubinemia, and maculopapular rash on both legs and arms. A steroid therapy was ineffective. One unit of WJ-MSCs 4/6 HLA-matched was obtained and expanded in vitro to $6.6 \times 10^{7}$ cells $\left(3.3 \times 10^{6}\right.$ cells $/ \mathrm{kg}$ body weight $)$ at passage 3 and then cryopreserved again. A normal karyotype and the absence of pathogenic contamination were confirmed and then, the WJ-MSCs were thawed, washed, and infused into the patient through a central venous catheter. Before the infusion, the grade of aGvHD was IV (gut staging: 4; skin staging: 3; liver staging: 3) according to standard aGvHD criteria proposed by Glucksberg et al. (37). Two days after infusing the WJ-MSCs, the severity of the diarrhea improved and subsequently subsided, the total bilirubin concentration decreased to a normal range in 6 days and the skin rash declined and disappeared in 7 days. On day 28 after the infusion, the recurrence of a III grade aGvHD (gut staging: 3; skin staging: 2; liver staging: 3) was treated with a 3/6 HLA-matched WJ-MSCs expanded to $7.2 \times 10^{6}$ cells $/ \mathrm{kg}$ at passage 3 with the complete disappearance of symptoms within 6 days. Despite continued cyclosporine administration, by day 25 after the second MSCs infusion, the IV aGvHD (gut staging: 4; skin staging: 3; liver staging: 2) flared up again and the patient received a third infusion of WJ-MSCs $\left(8.0 \times 10^{6}\right.$ cells $/ \mathrm{kg}$ at passage 4) matching 3/6 HLAs with total regression of manifestations 6 days after the WJ-MSCs infusion. Cyclosporine was slowly tapered 2 months after the third infusion, all immunosuppressive drugs were discontinued 12 months after HSCT and no chronic GvHD was observed.

The second patient was a 6-year-old boy transplanted with 2 units of umbilical cord blood 4 of 6 HLA matched for an acute lymphoblastic leukemia in second remission. On day 21, the patient developed hyperbilirubinemia and maculopapular rash.

He received a 3/6 matching HLA MSCs infusion expanded to $4.1 \times 10^{6} \mathrm{~kg}$ at passage 3 . Clinical manifestations of aGvHD intestinal, cutaneous or hepatic disappeared 5 days after the MSC infusion. Cyclosporine was tapered slowly 2 months after the MSCs infusion, all immunosuppressive drugs were discontinued 10 months after transplantation and no chronic GVHD was observed. No side effects and no severe infections incurred during or after each MSCs infusion in both patients.

In 2016, Boruczkowski et al. (38) described the use of WJ-MSCs for the treatment of 10 patients with steroid-resistant GvHD (7 patients diagnosed with aGvHD and 3 patients with cGvHD). After 1 to $3 \mathrm{WJ}-M S C$ infusions at a median dose of $1.5 \times 10^{6}$ cells $/ \mathrm{kg}$ of recipient body weight, a complete or partial response was observed in 4 patients with aGvHD and in 2 patients with cGvHD. Five out of 6 patients $(83.3 \%)$ from the responder group and only 1 out of 4 non-responders (25\%) survived the follow-up. The deaths occurred in patients with aGvHD. In 
the responder group, 2 patients showed complete remission of GvHD while symptoms were alleviated in 4 patients and the intensity of immunosuppressive therapy could be reduced. No serious adverse effects were observed. Interestingly, it seems that the therapy outcome did not correlate with the number of infusions, while the timing of infusion is crucial for therapy outcomes: in fact, 2 cases of complete remission were observed in patients who received only 1 infusion, but those patients received MSCs infusions 22 and 24 days after the GvHD diagnosis, which were the earliest cell applications in the aGvHD group (38).

In 2015 a second author, Wu et al. (39), futher documented that MSCs could be used for clinical treatment of refractory extensive cGvHD or aGvHD graded II-III. Twenty-four patients were included in the study: 8 patients suffered from aGvHD (4 grade III, 2 grade IV, 2 grade II), 16 patients cGvHD. All the patients received umbilical cord blood-derived MSCs infusion once. The average MSC dose given was $0.6 \times 10^{6} / \mathrm{kg}$ body weight (range $0.5 \sim 1.0 \times 10^{6} / \mathrm{kg}$ body weight). After a mean follow-up period of 1.5 years (range 1 month 2 years), 22 patients were still alive and 2 patients died: one due to IV aGvHD and one during liver transplant surgery.

The clinical manifestations of GvHD improved significantly in about one month after MSC infusion, with skin and oral mucosa involvement improving remarkably at the effective rates of $55.6 \%$ and $100 \%$, respectively. However, hepatic and pulmonary involvement underwent no significant improvements. At the last follow-up, the immunosuppressive agent therapy, after MSCs transfusion, was tapered and/or discontinued in 18 patients, while 2 patients with no remission and 2 patients, who achieved progressive disease (PD), maintained their basic therapies or required further increases of immunosuppressive agents. None of the surviving patients were found to have experienced a relapse of the primary disease, the incidence of infection or other transplant-related complications. No infusion-related toxicity was observed during or after the administration of MSCs. Table 1 provides an overview of the international literature regarding the management of Graft Versus Host Disease with WJ-MSCs infusions.

\section{Current Clinical Trials of WJ-MSCs}

The current trials regarding WJ-MSCs were investigated by a study on the website clinicaltrials.gov. Nine results were obtained using the following research queries: "Wharton's Jelly Mesenchymal Stem Cell”, "Wharton Jelly Stem Cell", "WJMSC", "WJ Mesenchymal Stem Cell" and "Wharton Jelly Cell". Two of these trials are complete, one has an unknown status, one is enrolling by invitation, one is not yet recruiting and four are recruiting (Table 2).

"Intracoronary Human Wharton's Jelly- Derived Mesenchymal Stem Cells (WJ-MSCs) Transfer in patients with acute myocardial infarction (AMI)" (NCT01291329) (40) is a completed trial held by the Navy General Hospital of Beijing. The purpose of the trial was to investigate the efficacy and safety of the intracoronary transfer of WJMSCs in patients with ST-segment elevation myocardial infarction. The Navy General Hospital of Beijing is also the sponsor of the "Intracoronary or intravenous infusion human Wharton' Jelly-derived Mesenchymal Stem Cells in patients with ischemic cardiomyopathy" (NCT-

Table 1. Literature overview for the management of graft versus host disease with WJ-MSCs infusions

\begin{tabular}{|c|c|c|c|c|c|c|c|}
\hline Authors & $\begin{array}{l}\text { No. of } \\
\text { patients }\end{array}$ & Disease & Grade GvHD & $\begin{array}{l}\text { Nr. of } \\
\text { W-MSCs } \\
\text { infusions }\end{array}$ & $\begin{array}{c}\text { Dose of WJ-MSCs infused } \\
\left(\times 10^{6} \text { cells per } \mathrm{kg}\right. \\
\text { body weight })\end{array}$ & $\begin{array}{l}\text { Side effect } \\
\text { during or } \\
\text { after } \\
\text { WJ-MSCs } \\
\text { infusions }\end{array}$ & Clinical outcome \\
\hline \multirow[t]{2}{*}{$\begin{array}{l}\text { Kang-Hsi Wu } \\
\text { et al. }\end{array}$} & 1 & $1 \mathrm{aGvHD}$ & IV & 3 & $\begin{array}{l}3.3 \text { (at passage } 3 \text { ), } 7.2 \\
\text { (at passage } 3 \text { ), } 8.0 \\
\text { (at passage } 4 \text { ) }\end{array}$ & None & CR \\
\hline & 1 & $1 \mathrm{aGvHD}$ & IV & 1 & 4.1 (at passage 3) & None & CR \\
\hline $\begin{array}{l}\text { Boruczkowsi } \\
\text { et al. }\end{array}$ & 10 & $\begin{array}{l}7 \text { aGvHD } \\
3 \text { cGvHD }\end{array}$ & $\begin{array}{l}6 \text { IV, } 1 \text { III } \\
3 \text { extensive }\end{array}$ & $1 \sim 3$ & $\begin{array}{l}1.5 \text { median dose } \\
\quad(\text { range } 1.1 \sim 4.9)\end{array}$ & None & $\begin{array}{l}2 \mathrm{CR}, 2 \mathrm{PR}, 3 \mathrm{NR} \\
2 \mathrm{PR}, 1 \mathrm{NR}\end{array}$ \\
\hline $\begin{array}{l}\text { Qiu-Ling Wu } \\
\text { et al. }\end{array}$ & 24 & $\begin{array}{l}8 \text { aGvHD } \\
16 \mathrm{cGvHD}\end{array}$ & $\begin{array}{l}2 \text { II, 4III, } 2 \text { IV } \\
12 \text { extensive, } \\
4 \text { localized }\end{array}$ & 1 & $\begin{array}{l}0.6 \text { median dose } \\
\quad(\text { range } 0.5 \sim 1.0)\end{array}$ & None & $\begin{array}{l}6 \mathrm{OR}, 2 \mathrm{NR} \\
14 \mathrm{OR}, 2 \mathrm{NR}\end{array}$ \\
\hline
\end{tabular}

WJ-MSCs: Wharton's jelly mesenchymal stem cells, aGvHD: acute Graft Versus Host Disease, cGvHD: crhonic Graft Versus Host Disease, NR: no response, CR: complete response, PR: partial response, OR: overall response (complete+partial response). 


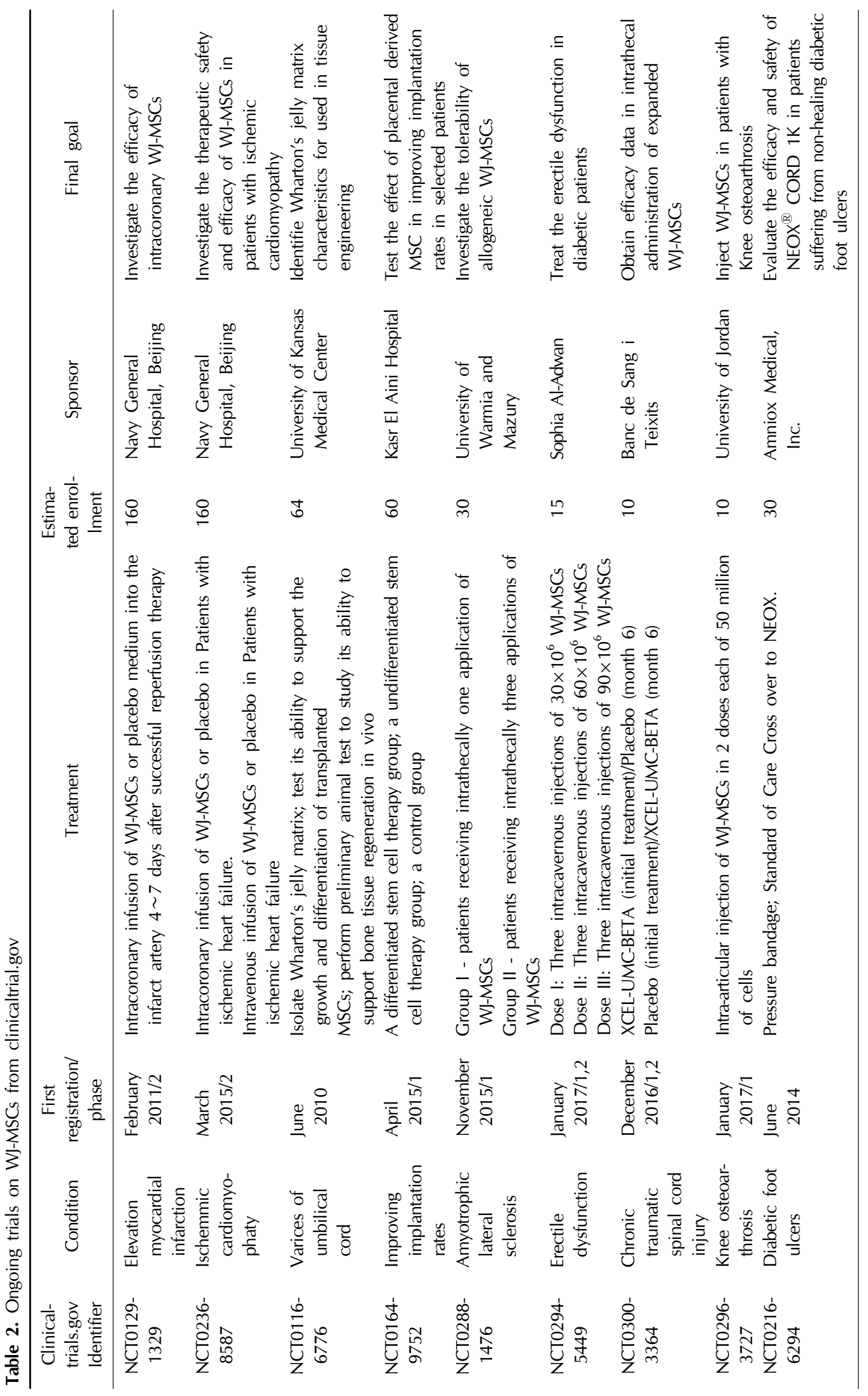


02368587) study, which, with similar objectives to the previous study, investigates the aptitude of WJ-MSCs to be differentiated into cardiomyocytes and endothelial cells and be integrated in vascular and ischemic cardiac tissue, improving heart function in patients with ischemic cardiomyopathy. To date, the study is not yet enrolling.

The other completed trial is "A research study looking at specific tissue of the umbilical cord" (NCT01166776), sponsored by the university of Kansas medical center. This study aims to investigate not the use of WJ-MSCs, but the WJ matrix without the cellular component as a scaffold for the implantation of MSCs with origins not otherwise specified.

The "Role of stem cells in improving implantation rates in Intracytoplasmic Sperm Injection ICSI patients" (NCT01649752) study status is unknown, since the completion date has passed and the status has not been updated in over two years. This study, sponsored by Kasr El Aini hospital, aimed to improve endometrial receptivity before transferring good embryos, taking advantage of the regenerative properties of MSCs. Both placenta-derived MSCs and WJ-MSCs were induced to differentiate in endometrium. This target was achieved by the placentaderived population, which was later deposited in the uterine cavity.

The study "Therapeutic treatment of amyotrophic lateral sclerosis" (ALS) (NCT02881476), carried out by university of Warmia and Mazury, is enrolling participants by invitation only. The WJ-MSCs are administrated intrathecally in one application for one group and in three applications for the second. The therapeutic outcome is hypothesized on the base of a neurocrine and paracrine effect of WJ-MSCs, which are investigated in terms of their capacity to influence the neurodegeneration present in ALS.

The study "Use of WJ in erectile dysfunction" (NCT02945449), is being conducted by Sophia Al-Adwan, university of Jordan. This study, which is now enrolling patient, is designed to evaluate the effect of intracavernous WJ-MSCs injection in diabetic patients with erectile dysfunction. The patients are divided in three groups, each receiving a different dose of WJ-MSCs. The efficacy is evaluated with doppler ultrasound and a sexual health inventory for men/international index of erectile function/erection hardness score questionnaire.

Another study, which is now recruiting patients is "Intrathecal administration of expanded WJ-MSCs in chronic traumatic spinal cord injury" (NCT03003364) by Banc de Sang i Teixits. This randomized, double-blind, single-dose, placebo-controlled trial examines the advan- tages that intrathecal administration of WJ-MSCs can produce in patients with chronic traumatic spinal cord disease. These effects are evaluated with scales, questionnaires, electrophysiology, imaging techniques and laboratory findings.

"Use of WJMSCs for knee osteoarthrosis" (NCT02963727) is a trial that evaluates the efficacy of intra-articular WJ-MSCs injection in patients with knee osteoarthrosis. This trial, sponsored by the university of Jordan, is recruiting patients and assesses the efficacy of the treatment by MRI at 12 months.

The last clinical trial founded as a result of our research is the "NEOX CORD $1 \mathrm{~K}$ vs standard of care in non-healing diabetic foot ulcers (CONDUCT I)" trial (NCT02166294), sponsored by Amniox Medical Inc., NEOX CORD $1 \mathrm{~K}$ is a cryopreserved umbilical cord allograft, containing only WJ matrix but not cells. The trial compares the time for closure of the ulcer using NEOX CORD $1 \mathrm{~K}$ versus the standard treatment, with pressure bandage.

\section{Conclusions}

As seen above, WJ possess the essential requisites to express a huge immunomodulation potential, which is, in fact, proven by early clinical data regarding the treatment of GvHD. Actual clinical trials hypothesize that WJ-MSCs can be used to improve patients' health or the outcome of life-threatening conditions.

Considering the increasing interest in the role of stem cells in regenerative medicine, the need for immunomodulatory treatment with lighter side effects and the spreading of allogenic transplantation as a therapy for consolidating haematological neoplasm as well as a saving therapy in several intractable diseases, WJ appears to play a leading role in the future of medicine and be the fulcrum of the newest research.

\section{Potential Conflict of Interest}

The authors have no conflicting financial interest.

\section{References}

1. Friedenstein AJ, Chailakhyan RK, Latsinik NV, Panasyuk AF, Keiliss-Borok IV. Stromal cells responsible for transferring the microenvironment of the hemopoietic tissues. Cloning in vitro and retransplantation in vivo. Transplantation 1974;17:331-340

2. Pittenger MF, Mackay AM, Beck SC, Jaiswal RK, Douglas R, Mosca JD, Moorman MA, Simonetti DW, Craig S, Marshak DR. Multilineage potential of adult human mesenchymal stem cells. Science 1999;284:143-147 
3. da Silva Meirelles L, Chagastelles PC, Nardi NB. Mesenchymal stem cells reside in virtually all post-natal organs and tissues. J Cell Sci 2006;119:2204-2213

4. Dominici M, Le Blanc K, Mueller I, Slaper-Cortenbach I, Marini F, Krause D, Deans R, Keating A, Prockop Dj, Horwitz E. Minimal criteria for defining multipotent mesenchymal stromal cells. The International Society for Cellular Therapy position statement. Cytotherapy 2006;8: 315-317

5. Zuk PA, Zhu M, Ashjian P, De Ugarte DA, Huang JI, Mizuno H, Alfonso ZC, Fraser JK, Benhaim P, Hedrick $\mathrm{MH}$. Human adipose tissue is a source of multipotent stem cells. Mol Biol Cell 2002;13:4279-4295

6. Abdulrazzak H, Moschidou D, Jones G, Guillot PV. Biological characteristics of stem cells from foetal, cord blood and extraembryonic tissues. J R Soc Interface 2010;7 Suppl 6:S689-706

7. Troyer DL, Weiss ML. Wharton's jelly-derived cells are a primitive stromal cell population. Stem Cells 2008;26:591599

8. Stenderup K, Justesen J, Clausen C, Kassem M. Aging is associated with decreased maximal life span and accelerated senescence of bone marrow stromal cells. Bone 2003; 33:919-926

9. Le Blanc K, Frassoni F, Ball L, Locatelli F, Roelofs H, Lewis I, Lanino E, Sundberg B, Bernardo ME, Remberger M, Dini G, Egeler RM, Bacigalupo A, Fibbe W, Ringdén O; Developmental Committee of the European Group for Blood and Marrow Transplantation. Mesenchymal stem cells for treatment of steroid-resistant, severe, acute graftversus-host disease: a phase II study. Lancet 2008;371:15791586

10. McElreavey $\mathrm{KD}$, Irvine $\mathrm{AI}$, Ennis $\mathrm{KT}$, McLean WH. Isolation, culture and characterisation of fibroblast-like cells derived from the Wharton's jelly portion of human umbilical cord. Biochem Soc Trans 1991;19:29S

11. Kuroda Y, Kitada M, Wakao S, Dezawa M. Mesenchymal stem cells and umbilical cord as sources for schwann cell differentiation: their potential in peripheral nerve repair. Open Tissue Eng Regen Med J 2011;4:54-63

12. Du T, Zou X, Cheng J, Wu S, Zhong L, Ju G, Zhu J, Liu G, Zhu Y, Xia S. Human Wharton's jelly-derived mesenchymal stromal cells reduce renal fibrosis through induction of native and foreign hepatocyte growth factor synthesis in injured tubular epithelial cells. Stem Cell Res Ther 2013;4:59

13. Moodley Y, Atienza D, Manuelpillai U, Samuel CS, Tchongue J, Ilancheran S, Boyd R, Trounson A. Human umbilical cord mesenchymal stem cells reduce fibrosis of bleomycin-induced lung injury. Am J Pathol 2009;175:303313

14. Lo Iacono M, Anzalone R, Corrao S, Giuffrè M, Di Stefano A, Giannuzzi P, Cappello F, Farina F, La Rocca G. Perinatal and Wharton's jelly-derived mesenchymal stem cells in cartilage regenerative medicine and tissue engineering strategies. Open Tissue Eng Regen Med J 2011;4:72-81
15. Scheers I, Lombard C, Najimi M, Sokal EM. Cell therapy for the treatment of metabolic liver disease: an update on the umbilical cord derived stem cells candidates. Open Tissue Eng Regen Med J 2011;4:48-53

16. Tamura M, Kawabata A, Ohta N, Uppalapati L, Becker KG, Troyer D. Wharton's jelly stem cells as agents for cancer therapy. Open Tissue Eng Regen Med J 2011;4:39-47

17. Deuse T, Stubbendorff M, Tang-Quan K, Phillips N, Kay MA, Eiermann T, Phan TT, Volk HD, Reichenspurner H, Robbins RC, Schrepfer S. Immunogenicity and immunomodulatory properties of umbilical cord lining mesenchymal stem cells. Cell Transplant 2011;20:655-667

18. Zhou C, Yang B, Tian Y, Jiao H, Zheng W, Wang J, Guan F. Immunomodulatory effect of human umbilical cord Wharton's jelly-derived mesenchymal stem cells on lymphocytes. Cell Immunol 2011;272:33-38

19. Selmani Z, Naji A, Zidi I, Favier B, Gaiffe E, Obert L, Borg C, Saas P, Tiberghien P, Rouas-Freiss N, Carosella ED, Deschaseaux F. Human leukocyte antigen-G5 secretion by human mesenchymal stem cells is required to suppress $\mathrm{T}$ lymphocyte and natural killer function and to induce CD4+ CD25highFOXP3 + regulatory T cells. Stem Cells 2008;26: 212-222

20. Weiss ML, Anderson C, Medicetty S, Seshareddy KB, Weiss RJ, VanderWerff I, Troyer D, McIntosh KR. Immune properties of human umbilical cord Wharton's jelly-derived cells. Stem Cells 2008;26:2865-2874

21. Prasanna SJ, Gopalakrishnan D, Shankar SR, Vasandan AB. Pro-inflammatory cytokines, IFNgamma and TNFalpha, influence immune properties of human bone marrow and Wharton jelly mesenchymal stem cells differentially. PLoS One 2010;5:e9016

22. La Rocca G, Anzalone R, Corrao S, Magno F, Loria T, Lo Iacono M, Di Stefano A, Giannuzzi P, Marasà L, Cappello F, Zummo G, Farina F. Isolation and characterization of Oct-4+/HLA-G + mesenchymal stem cells from human umbilical cord matrix: differentiation potential and detection of new markers. Histochem Cell Biol 2009;131:267282

23. Djouad F, Charbonnier LM, Bouffi C, Louis-Plence P, Bony C, Apparailly F, Cantos C, Jorgensen C, Noël D. Mesenchymal stem cells inhibit the differentiation of dendritic cells through an interleukin-6-dependent mechanism. Stem Cells 2007;25:2025-2032

24. Pontikoglou C, Deschaseaux F, Sensebé L, Papadaki HA. Bone marrow mesenchymal stem cells: biological properties and their role in hematopoiesis and hematopoietic stem cell transplantation. Stem Cell Rev 2011;7:569-589

25. Tipnis S, Viswanathan C, Majumdar AS. Immunosuppressive properties of human umbilical cord-derived mesenchymal stem cells: role of B7-H1 and IDO. Immunol Cell Biol 2010;88:795-806

26. Che N, Li X, Zhou S, Liu R, Shi D, Lu L, Sun L. Umbilical cord mesenchymal stem cells suppress B-cell proliferation and differentiation. Cell Immunol 2012;274: $46-53$ 
27. Ribeiro A, Laranjeira P, Mendes S, Velada I, Leite C, Andrade P, Santos F, Henriques A, Grãos M, Cardoso CM, Martinho A, Pais M, da Silva CL, Cabral J, Trindade H, Paiva A. Mesenchymal stem cells from umbilical cord matrix, adipose tissue and bone marrow exhibit different capability to suppress peripheral blood $\mathrm{B}$, natural killer and $\mathrm{T}$ cells. Stem Cell Res Ther 2013;4:125

28. Nekanti U, Mohanty L, Venugopal P, Balasubramanian S, Totey S, Ta M. Optimization and scale-up of Wharton's jelly-derived mesenchymal stem cells for clinical applications. Stem Cell Res 2010;5:244-254

29. Fong CY, Richards M, Manasi N, Biswas A, Bongso A. Comparative growth behaviour and characterization of stem cells from human Wharton's jelly. Reprod Biomed Online 2007;15:708-718

30. Nekanti U, Rao VB, Bahirvani AG, Jan M, Totey S, Ta M. Long-term expansion and pluripotent marker array analysis of Wharton's jelly-derived mesenchymal stem cells. Stem Cells Dev 2010;19:117-130

31. Weiss ML, Medicetty S, Bledsoe AR, Rachakatla RS, Choi M, Merchav S, Luo Y, Rao MS, Velagaleti G, Troyer D. Human umbilical cord matrix stem cells: preliminary characterization and effect of transplantation in a rodent model of Parkinson's disease. Stem Cells 2006;24:781-792

32. Karahuseyinoglu S, Cinar O, Kilic E, Kara F, Akay GG, Demiralp DO, Tukun A, Uckan D, Can A. Biology of stem cells in human umbilical cord stroma: in situ and in vitro surveys. Stem Cells 2007;25:319-331

33. Pavletic SZ, Fowler DH. Are we making progress in GVHD prophylaxis and treatment? Hematology Am Soc Hematol Educ Program 2012;2012:251-264

34. Blazar BR, Murphy WJ, Abedi M. Advances in graft-versus-host disease biology and therapy. Nat Rev Immunol 2012;12:443-458
35. Deeg HJ. How I treat refractory acute GVHD. Blood 2007; 109:4119-4126

36. Wu KH, Chan CK, Tsai C, Chang YH, Sieber M, Chiu TH, Ho M, Peng CT, Wu HP, Huang JL. Effective treatment of severe steroid-resistant acute graft-versus-host disease with umbilical cord-derived mesenchymal stem cells. Transplantation 2011;91:1412-1416

37. Glucksberg H, Storb R, Fefer A, Buckner CD, Neiman PE, Clift RA, Lerner KG, Thomas ED. Clinical manifestations of graft-versus-host disease in human recipients of marrow from HL-A-matched sibling donors. Transplantation 1974; 18:295-304

38. Boruczkowski D, Gładysz D, Rumiński S, CzaplickaSzmaus I, Murzyn M, Olkowicz A, Kałwak K, Mielcarek M, Drabko K, Styczyński J, Markiewicz M, Pawelec K, Boruczkowski M, Ołdak T. Third-party Wharton's jelly mesenchymal stem cells for treatment of steroid-resistant acute and chronic graft-versus-host disease: a report of 10 cases. Turk J Biol 2016;40:493-500

39. Wu QL, Liu XY, Nie DM, Zhu XX, Fang J, You Y, Zhong ZD, Xia LH, Hong M. Umbilical cord blood-derived mesenchymal stem cells ameliorate graft-versus-host disease following allogeneic hematopoietic stem cell transplantation through multiple immunoregulations. J Huazhong Univ Sci Technolog Med Sci 2015;35:477-484

40. Gao LR, Chen Y, Zhang NK, Yang XL, Liu HL, Wang ZG, Yan XY, Wang Y, Zhu ZM, Li TC, Wang LH, Chen HY, Chen YD, Huang CL, Qu P, Yao C, Wang B, Chen GH, Wang ZM, Xu ZY, Bai J, Lu D, Shen YH, Guo F, Liu MY, Yang Y, Ding YC, Yang Y, Tian HT, Ding QA, Li LN, Yang XC, Hu X. Intracoronary infusion of Wharton's jelly-derived mesenchymal stem cells in acute myocardial infarction: double-blind, randomized controlled trial. BMC Med 2015;13:162 